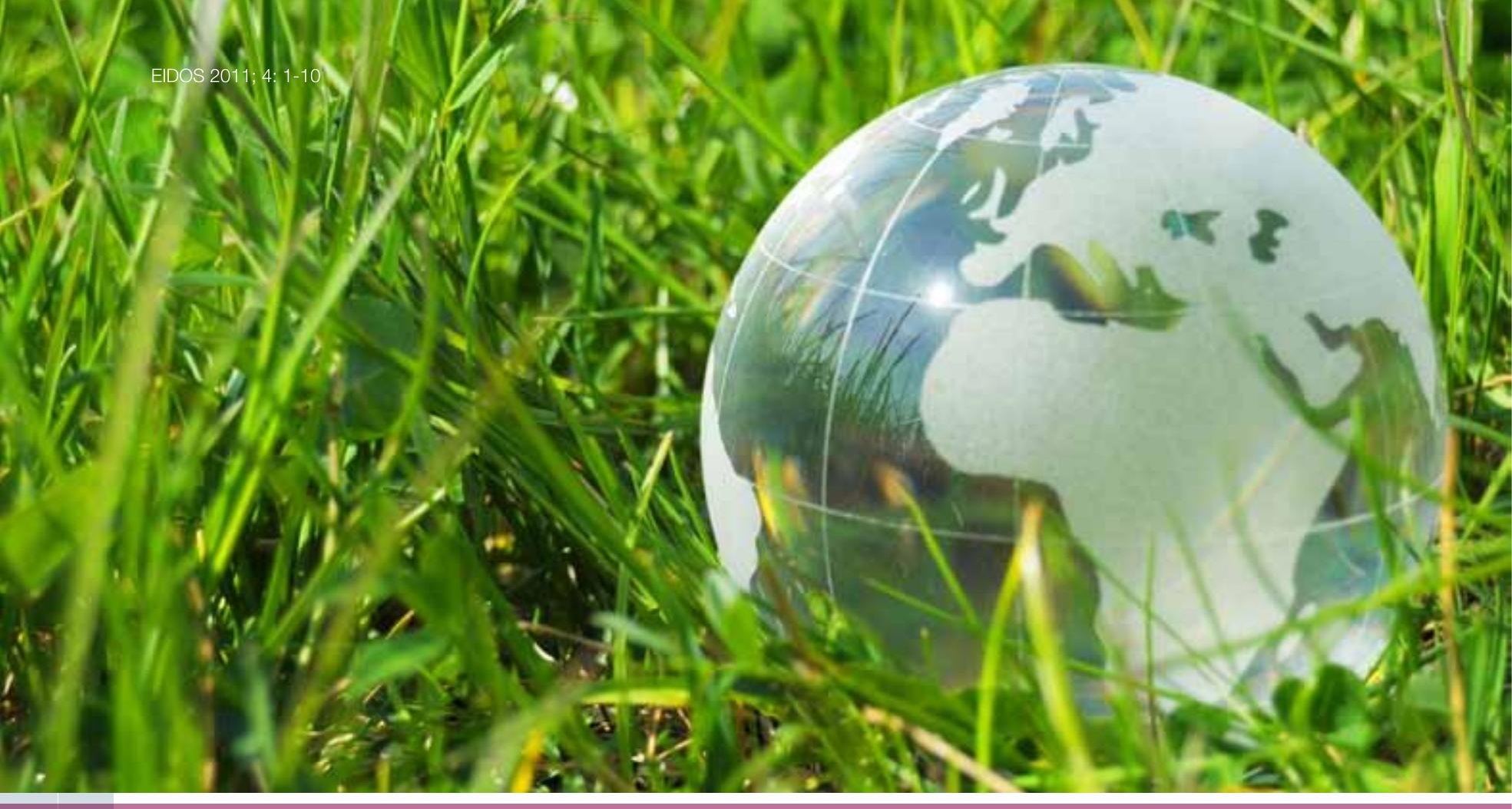

EIDOS, 4

Marzo-agosto 2011, 74-83

ISSN:1390-499X

elSSN:1390-5007

\title{
A REVIEW ON FRAMEWORKS FOR DECISION SUPPORT SYSTEMS FOR ENVIRONMENTAL DOMAINS
}

M. Sokolova ${ }^{1}$, Universidad Estatal del Sur-Oeste de Rusia

Recepción/Received: 2011-03-03

A. Fernández-Caballero, F. Gómez, Universidad de Castilla-La Mancha

Aceptación/Accepted: 2011-07-11

Publicado/Published: 2011-08-05

Resumen -La revisión se dedica a relatar investigaciones a presentar una visión general de la investigación actuales en las áreas de análisis de sistemas complejos y la toma de decisiones por medio de herramientas inteligentes, incluyendo aquellas que son basadas en agentes. También compara las metodologías orientadas a agentes y los marcos de apoyo a la decisión. Por otra parte, tambien se presenta conclusiones sobre la necesidad de tener un framework que combine las dos características.

Palabras clave -Toma de decisiones, agentes, metodología, framework

Abstract -The review is devoted to related research and presents an overview of current research in areas of complex system analysis and decision making by the means of intelligent tools, including those that are agent-based. It also compares existing agent-oriented methodologies and frameworks for decision support. Furthermore, the chapter makes conclusions about the necessity of general framework, which would combine characteristics of the former and the latter.

Keywords -Decision making, agents, methodology, framework 


\section{INTRODUCCIÓN}

Decision making is the final goal of a decision support system (DSS), and, for environmental domains, it is multisectorial by nature. In practice, decisions can be taken by single authorities or by a group of responsible decision makers. Nowadays, decision makers use DSS, which serve as an informational background, enabling real-time simulation and further decision generation.

Informational support, received with DSS, helps to mobilize and allocate resources, to set priorities and to share successful patterns and strategies in area of public health, air and water resources, and other.

Nowadays, there are many definitions of what a DSS is. For example, DSS can be designed as a specific class of computerized information systems that support decisionmaking activities. A properly designed DSS is an interactive software-based system intended to help decision makers in compiling useful information from raw data, documents, personal knowledge, and patterns to identify and solve problems and to make decisions.

\section{DECISION SUPPORT SYSTEMS IN ACADEMY AND RESEARCH}

Decision support systems have significantly evolved and turned into essential tools. As it is noted in [1],[2], modern institutions and corporations tend to become more widespread and to lose rigidness of their organizational structures. On the other hand, the larger number of senior and medium executives consult with DSS and have daily hands-on experience with them. Thus, a DSS has become a crucial part of organization and not just a stand-alone application [1], [3], [4], [5], [6], and [7].

As it is reported in [1], [8], agent technology has emerged as a promising solution to meet the requirements in order to provide decision support for complex domains.

As a rule, agents within the decision support systems must carry out the following functions:

- to search for valuable information and to retrieve it;

- for multiple scaling in case of heterogeneous sources of income and outcome information;

- to provide intercommunication between the system and the external information sources (e.g. sensors, remote equipment);

- to check input data for consistency and to preprocess it;

- to execute data mining procedures;

- to experiment with different alternatives and to make recommendations;
- to organize human-computer interactions.

Modern "decision support systems" and "expert systems" (ES) are commonly based on intelligent agents, and the concepts of DSS as well those of ES have also been modified [9], [10], [11]. For example, medicine is a traditional field of DSS application, and some recent academic reports deal with examples of novel usage of agent-based DSS for home and hospital care, pre-hospital emergency care and health monitoring and surveillance [12].

One of such an application is a distributed DSS for brain tumor diagnosis and prognosis [12], [13], where agents use both data mining methods and decision making techniques. An application of remote control of patients via clinical DSS is created on the basis of multiagent methodology, and results in the creation of the SAPHIRE multiagent system. There are many reasons to apply the agent paradigm: the necessity to interact in heterogeneous distributed environments, the need to provide instantaneous communication of autonomous components in a reactive manner, or the possibility to dynamically create and eliminate agents. It this application, the agents provide all the vital functions of the system.

In [14] the outcomes of the construction and usage of an agent-based environmental monitoring system are presented. It is aimed to provide measurements of meteorological information and air pollution, to analyze them and to generate alarm signals. The system is created by means of the intelligent platform "Agent Academy". The system has a three-leveled organizational structure where data preprocessing, its manipulation and distribution are carried out. The necessary steps for data transformation are executed by the following types of intelligent agents: Diagnosis agents, Alarm agents, Database agents and Distribution agents.

In another article, the authors report about the application of the agent paradigm for the evaluation of sociallyoriented advertising campaigns aimed to affect consumers' behavior [15]. The authors create social communication models to simulate a public response to mass-media influence and introduce a social grid populated with autonomous consumer agents. This grid is also used to evaluate possible outcomes of the public campaign on water demand control.

Another situation assessment is carried out by an agentbased system created with the MASDK tool [16]. The authors present their approach in situation assessment and explain its possible application in different problem areas.

Another approach to complex situation assessment has been presented [17]. The authors have accepted the JDL (Joint Directors of Laboratories) model as a basis for situation awareness. Their new approach to situation assessment learning is described and the structure of the MAS is presented as well. The agents act within the four levels of the hierarchical JDL-model. 
In another reference [18], the authors present the framework of a decision support system for water management in the Mediterranean islands, coupling a multi-agents system with a geographic information system. The platform developed makes it possible for users to better understand the current operation of the system, to apprehend the evolution of the situation, and to simulate different scenarios according to the selected water policies and the climatic changes hypothesis. Recently, the development and experimental evaluation of an Internet-enabled multiagent prototype called AgentStra [19], for developing marketing strategies, competitive strategies and associated e-commerce strategies has been introduced.

On the other hand, specialists working with environmental sciences and public health store huge volumes of relevant information about pollutants and human health. Continuous processing and maintenance of the information requires substantial efforts from the practitioners and professionals, not only while handling and storing data, but also when interpreting it. Actually, it seems very hard to handle all the data without using data mining (DM) methods, which can autonomously dig out all the valuable knowledge that is embedded in a database without human supervision, providing a full life-cycle support of data analysis. Using such techniques as clustering, classification, logical and association rule-based reasoning, and other methods, which are highly demanded for comprehensive environmental data analysis. For instance, DM techniques for knowledge discovery and early diagnostics are utilized for early intervention in developmentally-delayed children [20].

Reference [21] outlines the MAS "Instrumented City Data Base Analyst", which is aimed to reveal correlations between human health and environmental stress factors (traffic activity, meteorological data, noise monitoring information and health statistics) by using a wide range of DM methods, including regression analysis, neural networks, ANOVA and others. The architecture of the system counts a number of modules placed within four levels. The multiagent structure includes specific modeling agents, which create models for the environmental stress factors, and are then harmonized by the model co-ordination agent. The Data Abstractor is an agent that gets information from sensors, fuses it and preprocesses it. Interaction with humans is provided by the Reception agent.

Reference [22] provides a survey of intelligent-based system for decision support which supports clinical management and research. The author gives a brief introduction into DSS and agent-based DSS, and gives an example of a Neonatal Intensive

Care Unit system. In the high-level diagram of the proposal there is the solution manager service, which represents an Intelligent DSS (IDSS). The Analytical Processor of the IDSS joins different types of agents: functional, processing, human and sub-agents, and this processor is aimed to detect trends and patterns the data of interest.

A group of researchers [23] have presented a number of works dedicated to decision making support in a waste water treatment plant (WWTP). In order to provide an intelligent model and control for the WWTP, the authors use eight sorts of autonomous agents which support the decision-making process. The agents, which interact with the WWTR and the users are the Monitoring Agent and the Actuation Agent. The Monitoring Agent captures some data from WWTP through the system of sensors, supplies retrospective information, displays it and supplies a basic alarm system. The Actuation Agent analyzes some WWTP parameters, suggests orders, processes alarms and reacts in order to solve them. And, lastly, there are User Agents, which are responsible for the organization of the human-user interface, which accept orders and transform them into goals for the multiagent system. It also receives and displays information and recommendations, and supplies justifications to certain actions. The Monitoring Agent, Actuation Agent and User Agents interact with the "nucleus" of the multiagent system through the communication system, and then, data is analyzed and transformed respectively by the Modeling Agent, the Predictive Agent, and the Numerical Control Agent. Then it is tested and used by the Expert Reasoning Agent and the Experience Reasoning Agent. The Modeling Agent accepts a selection of simulation and control models, enables and disables the simulation and automatic control of the WWTP. As it incorporates a number of modeling methods, it applies them to simulate specific processes of WWTP and suggests control actions. The Predictive Agent is dedicated exclusively to task prediction, interpreting the results of simulations and selecting the best models. The Numerical Control Agent determines the best control algorithm among the ones available from the Modeling agent. The Expert Reasoning Agent contains the expert knowledge and serves as a rule-based data base, which gives permission to receive any new knowledge. The Experience Reasoning Agent learns new experiences provided by an expert or another source of knowledge whenever a new problem is solved.

Ceccaroni et al. [24] continue to develop the idea and implementation of the DSS noted above and offer an environmental decision support system related with a domain 
ontology. The authors aim to check if incorporation of an ontology and DSS, based on rule-based reasoning and case-based reasoning, can improve the decisions that are generated. The article describes the OntoWEDSS architecture, which is derived from the model of the DSS for WWTP. It has an ontology embedded and a reasoning module, which serves to facilitate knowledge sharing and reuse. The reasoning module is modified, and contains rule-based reasoning, case-based reasoning and ontology-based reasoning.

In the publication dedicated to working out an interdisciplinary approach to solving conflicts in water domain [25], the authors bring together the problem of managing a complex system. The problem consists a complex application domain (water resources)(A) as well as a wide range of decision makers, experts and other personnel (B). In this work the authors attempt to deal with this composite system and discuss the creation of a conceptual framework, which would be able to solve possible conflicts in system A and simultaneously solve problems in the application domain. The framework presented in [26] is based on the application of the agency paradigm to the Integrated Sustainability Assessment (ISA) Cycle.

The ambition of ISA is to provide an international scientific society with a general framework, which would include a variety of assessment tools and methods. Then, the author proposes a two-track strategy: intent to use the current portfolio of ISA tools as efficiently and effectively as possible, and contribute to the generation of new ISA tools.

Another work [27] presents a study dedicated to application of an integrated assessment approach to catchment management. In [28] a nodal network-based approach to the case of water resource allocation and management is applied. The proposed framework uses a nodal network structure which changes its form depending on the type of decision being made. The framework produces scenarios in the form of "what if" questions related to policy and management of the case of study. The framework presented in [27] is centered on the need for improved techniques of uncertainty and sensitivity analysis that can be taken as a measure of confidence for ranking decisions and making a choice.

An approach for the integrated assessment of both technical and valuation uncertainties during decision making, based on Life Cycle Assessment has also been presented [29]. The approach is built on three conditions: placing appropriate bounds on particular aspects, non-overlapping alternatives, and conducting a sensitivity analysis for valuating uncertainties.
Also, a multi-layer tool for socio-environmental simulation has been proposed [30]. The authors have developed a hybrid system, comprised by CORMAS (COmmon pool Resources and Multi-Agents Systems) and a language $Q$. CORMAS is a system, based on the multiagent paradigm, which describes the interactions between the natural environment and humans. $Q$ is a language for describing complex interaction scenarios among agents. The simulator has a two-layered architecture and counts social and environmental simulation layers. Social simulation realizes decision making, negotiation, and collaboration. Environmental simulation is dedicated to the diffusion of environmental changes and to the agents' behavior. The system has been applied to fire fighting, for example, where two types of agents of various levels of responsibility (the FireBoss and FireFighter agents) are implied.

To summarize all the papers reviewed, it is possible to classify the following types of environmental information systems (EIS):

1. Local systems. This type of EIS is a kind of "island solution", which is dedicated to the evaluation or assessment of a few parameters or indicators, In other words, these systems are designed to solve a specific problem. For example, one could find a system that provides a specific assessment of parameters for a specific case study or for a limited area. Domain ontologies for such systems are limited, although they may suffer from possible heterogeneity. As a rule, such systems are effective when working within the application domain but are sensitive to any unforeseen changes.

2. Multi-functional systems. These systems provide multiple analyses of input information, can be based upon hybrid techniques, and possess tools and methods of data pre- and post-processing, modeling and simulation. Multi-functional systems are less sensitive to changes in the application domain as they possess tools to manage uncertainty and heterogeneity.

3. Methodologies and frameworks of EIS development. Frameworks support all the stages of EIS life cycle, starting with the initial system planning. They include system analysis and domain (problem) analysis phases, and then assist and provide EIS design, coding, testing, implementation, deployment and maintenance. In this case, the consolidated cooperation of specialists from various domains with various backgrounds is necessary. Methodologies/frameworks are based upon interdisciplinary approaches and system analysis. 
TABLE 1 RESEARCH PAPERS DEDICATED TO DECISION SUPPORT SYSTEMS IN COMPLEX SYSTEMS

\begin{tabular}{|c|c|c|c|}
\hline Reference & Field of application & Purpose & Data mining approach \\
\hline \multicolumn{4}{|c|}{ Local systems } \\
\hline [20] & $\begin{array}{l}\text { The author presents results of application of } \\
\text { data mining to early intervention for } \\
\text { developmentally-delayed children. }\end{array}$ & $\begin{array}{l}\text { To explore the hidden knowledge among } \\
\text { medical history data. }\end{array}$ & $\begin{array}{l}\text { Decision trees, } \\
\text { association rules }\end{array}$ \\
\hline [32] & $\begin{array}{l}\text { The impact of outdoor air pollution on infant } \\
\text { mortality. }\end{array}$ & $\begin{array}{l}\text { To confirm that outdoor air pollution } \\
\text { contributes to illness and death in adults } \\
\text { and children. }\end{array}$ & $\begin{array}{l}\text { Exposure-response } \\
\text { functions. }\end{array}$ \\
\hline [12] & $\begin{array}{l}\text { The authors describe a complex environmental } \\
\text { process controlled by an agent-based system. }\end{array}$ & $\begin{array}{l}\text { To improve some previous works that are } \\
\text { not based on agents. }\end{array}$ & Software agents. \\
\hline [33] & $\begin{array}{l}\text { The results obtained from two different neural } \\
\text { networks are compared. }\end{array}$ & $\begin{array}{l}\text { To predict traffic related } \mathrm{PM}_{2.5} \text { and } \mathrm{PM}_{10} \\
\text { emissions by an artificial neural networks } \\
\text { based model. }\end{array}$ & $\begin{array}{l}\text { Feed Forward and } \\
\text { Radial Basis Function } \\
\text { neural networks. }\end{array}$ \\
\hline [34] & $\begin{array}{l}\text { The analysis is based on the estimation of the } \\
\text { spectral properties of indoor and outdoor } \\
\text { pollution particles and the estimation of the } \\
\text { integral time scale using the autocorrelation } \\
\text { properties of the series. }\end{array}$ & $\begin{array}{l}\text { To investigate the temporal behavior of } \\
\text { the indoor and outdoor particles' sizes. }\end{array}$ & $\begin{array}{l}\text { Rotated Principle } \\
\text { Component Analysis } \\
\text { and Positive Matrix } \\
\text { Factorization. }\end{array}$ \\
\hline [13] & $\begin{array}{l}\text { The definition of a decision support system that } \\
\text { deploys an ad hoc agent-based architecture in } \\
\text { order to negotiate a distributed diagnostic tool } \\
\text { for brain tumors. Implements data mining } \\
\text { techniques, transfers clinical data and extracts } \\
\text { information. }\end{array}$ & $\begin{array}{l}\text { To improve the quality of brain tumor } \\
\text { diagnosis and prognosis. }\end{array}$ & Multi-agent system. \\
\hline \multicolumn{4}{|c|}{\begin{tabular}{|l} 
Multi-functional systems \\
\end{tabular}} \\
\hline [14] & $\begin{array}{l}\text { The paper introduces a multiagent system for } \\
\text { monitoring and assessing air-quality attributes. }\end{array}$ & $\begin{array}{l}\text { The authors offer a solution for } \\
\text { continuous surveillance and on- line } \\
\text { decision-making. }\end{array}$ & Software agents. \\
\hline [35] & $\begin{array}{l}\text { The authors present a system for agent-based } \\
\text { simulation and support for clinical processes. }\end{array}$ & $\begin{array}{l}\text { To increase the efficiency of hospital } \\
\text { process management. }\end{array}$ & $\begin{array}{l}\text { Agent-based } \\
\text { simulation. }\end{array}$ \\
\hline [36] & $\begin{array}{l}\text { It introduces a system capable of belief } \\
\text { revision for situation assessment. }\end{array}$ & $\begin{array}{l}\text { To enhance quality of situation } \\
\text { assessment. }\end{array}$ & $\begin{array}{l}\text { Situation Description } \\
\text { Language. }\end{array}$ \\
\hline [37], [38] & $\begin{array}{l}\text { A distributed approach to the construction of } \\
\text { DSS is proposed. The authors present an } \\
\text { abstract architecture for a multiagent decision } \\
\text { support system and present case studies. }\end{array}$ & To facilitate decision making process. & $\begin{array}{lr}\text { Decision } & \text { support } \\
\text { systems, } & \text { agent } \\
\text { systems. } & \end{array}$ \\
\hline [39] & $\begin{array}{l}\text { The study resents results of research that is } \\
\text { dedicated to mining decisions from user } \\
\text { profiles in order to find common preferences } \\
\text { for different roles of decision makers } \\
\text { participating in emergency response operations. }\end{array}$ & $\begin{array}{l}\text { Facilitating a fast and clear description of } \\
\text { situation, the generation of effective } \\
\text { solutions for situation management, the } \\
\text { selection of a right decision maker and } \\
\text { supplying him/her necessary data. }\end{array}$ & $\begin{array}{l}\text { Software } \\
\text { decision trees }\end{array}$ \\
\hline [40] & $\begin{array}{l}\text { This paper reviews the range of approaches to } \\
\text { assessment now in use, proposes a framework } \\
\text { for integrated environmental health impact } \\
\text { assessment, and discusses some of the } \\
\text { challenges involved in conducting integrated } \\
\text { assessments to support policy. }\end{array}$ & $\begin{array}{l}\text { To bring together existing methods } \\
\text { within a more coherent system and to } \\
\text { extend these methods in order to provide } \\
\text { a more comprehensive methodology for } \\
\text { assessing complex, systemic risks and } \\
\text { policies. }\end{array}$ & $\begin{array}{l}\text { Risk assessment } \\
\text { techniques. }\end{array}$ \\
\hline [41] & $\begin{array}{l}\text { A decision support system that aims to prepare } \\
\text { actors in a crisis situation by a decision-making } \\
\text { support system is presented. }\end{array}$ & $\begin{array}{l}\text { To ensure swift and efficient reaction of } \\
\text { actors in emergency situations. }\end{array}$ & $\begin{array}{lr}\text { Decision } & \text { support } \\
\text { system, } & \text { software } \\
\text { agents. } & \end{array}$ \\
\hline \multicolumn{4}{|c|}{ Methodologies of EIS development. } \\
\hline [16] & $\begin{array}{l}\text { Authors present a methodology for the } \\
\text { engineering of agent-based systems, which } \\
\text { include the Multi Agent System Development } \\
\text { Kit, based on the implemention of the Gaia } \\
\text { methodology. }\end{array}$ & $\begin{array}{l}\text { To maintain the integrity of solutions } \\
\text { produced at different stages of the } \\
\text { development process }\end{array}$ & Software agents. \\
\hline [42] & $\begin{array}{l}\text { The author presents an approach to composite } \\
\text { decision making for complex domains and } \\
\text { demonstrates a number of case studies. }\end{array}$ & $\begin{array}{l}\text { To work out a new approach to complex } \\
\text { system study }\end{array}$ & $\begin{array}{l}\text { Hybrid methods from } \\
\text { various disciplines }\end{array}$ \\
\hline [26] & $\begin{array}{l}\text { A cross-sectoral approach to assessing } \\
\text { sustainable development is introduced }\end{array}$ & $\begin{array}{l}\text { To create tools able to deal with complex, } \\
\text { multi-dimensional phenomena }\end{array}$ & $\begin{array}{l}\text { Integrated } \\
\text { Sustainability } \\
\text { Assessment tools }\end{array}$ \\
\hline [43] & $\begin{array}{l}\text { An integrated environment for embedding } \\
\text { intelligence in newly created agents through the } \\
\text { use of Data Mining techniques is presented. }\end{array}$ & $\begin{array}{l}\text { To facilitate dynamic usage of data } \\
\text { mining extracted knowledge. }\end{array}$ & $\begin{array}{l}\text { An integrated } \\
\text { development } \\
\text { framework known as } \\
\text { "Agent Academy" }\end{array}$ \\
\hline [44] & $\begin{array}{l}\text { The author introduce a new engineering } \\
\text { discipline "Situational Method Engineering" } \\
\text { that is aimed in constructing new methods and } \\
\text { the associated tools (or in adaption existing } \\
\text { ones) to every Information System } \\
\text { Development project. }\end{array}$ & $\begin{array}{l}\text { To create new situation-specific methods } \\
\text { both by reengineering of existing method } \\
\text { components (co-called "chunks") or by } \\
\text { creation of new ones. }\end{array}$ & $\begin{array}{lr}\text { Different } & \text { methods } \\
\text { from } & \text { various } \\
\text { disciplines. } & \end{array}$ \\
\hline
\end{tabular}


Table 1 shows research reports, books and articles that were revised and classified by their functions and goals.

The table is organized in such a way, that the complexity of works cited increases towards the bottom of the table. Many reported works have characteristics of local systems, summed up also propose approaches to more complex and integrated data analysis. The problem lies in the high complexity of domains, which makes the creation of overall general methodologies impossible. These papers are characterized with high flexibility, but knowledge gained cannot be easily transferred to other projects. The systems, revised in the "Multi-functional systems" part of the Table 1, are cases of "Flexibility" methodological approach, in agreement with classification introduced by Harmsen [31].

The methodologies of EIS development presented in the Table offer more composite approaches, and some of them can exemplify "Controlled flexibility" approach [31], that is a compromise between rigid standardization and ad-hoc engineering. The Table 1 gathers research reports and articles, which offer methodologies and frameworks for decision making in complex domains. These works gave more general view on problem domains, introduce systematization abstractions and methods of control.

\section{AGENT-BASED FRAMEWORKS}

\section{FOR DECISION SUPPORT SYSTEMS}

Agent-Oriented Software Development is one of the recent contributions to the field of Software Engineering. Agent-oriented methodologies provide a user with necessary theoretical base and a set of practical tools for multiagent system creation. Besides, they introduce abstractions that support system creation. To date numerous methodologies for agent-oriented software development are being practiced [45], [46], [47], and [48]. However, their application to real-world problems is still limited due to their lack of maturity. Evaluating their strengths and weaknesses is an important step towards developing better methodologies in the future.

In this connection it seems reasonable to mention that, in spite of a variety of existing methodologies, the most part of them origins from object-oriented methods.

Let us take a view on the principal characteristics of most known methodologies.

The PASSI methodology has its origins in object-oriented and agent paradigms and unify them using

The Unified Modeling Language (UML) notation [49]. It offers a detailed lifecycle development process, that covers stages starting from initial requirements and includes deployment and the social model of agent-based systems [50].

The Tropos methodology put an emphasis on requirements analysis and, hence, on modeling goals, and on establishing their relations with system entities (actors, tasks, and resources) [51]. It is based on the Belief Desire Intention (BDI) model of agent [42].

The Prometheus methodology is based on agent-oriented paradigm, and brings rich possibilities for descriptions of agent system in whole and each agent in detail, that can be applied both to BDI and non-BDI agents [52], [53].

MAS-CommonKADS is based on both CommonKADS and object-oriented (OO)-based methodologies. This enables the developer to build agentbased systems while leveraging the experience of pre-agent methodologies and employing familiar techniques and diagrams [54].

The methodology of Fusion inspired creation of the Gaia methodology, which provides an easily-understandable approach [55], [56]. It offers abstractions and diagrams that support multiagent systems analysis and design phases [56]. The Gaia v.2 is the next version of the Gaia methodology that is more oriented to designing and building systems in complex, open environments [45].

The Rational Unified Process (RUP) process has three "siblings": the methodologies RAP, ADELFE and MESSAGE [57]. ADELFE is oriented to deal with emergent systems and that is why propose usage of cooperative and self-organize agents [58], [59]. This methodology is based on the and thus follows its main phases: preliminary requirements, final requirements, analysis and design, and uses UML and Agent-based Unified Modeling Language (AUML) notations [60], [45].

MESSAGE and INGENIAS assert both RUP-based approach and utilize the modelling language of Agent-Object-Relationship (AOR) [61], [62], [63], [64], and [65]. The first one provides extended models for analysis and design, and the second one propose a metamodel organization of a multiagent system and provides support on all the stages of system lifecycle.

The MAS-Common KADs methodology heredities from object-oriented methodology Object Modelling Technique (OMT) and it extends the CommonKADS models, adapting them to agent-oriented programming. 
The AAll also takes ideas of the OMT methodology and deepens into relations between the agent and the environment with regards to the interaction model [55]. The AAll inspired the MaSE, which provides environments to support the development stages and can be applied to various heterogeneous domains [66]. Last, the OPEN approach supports design of AgentOPEN agents [67].

\section{CONCLUSION}

To conclude with, it can be said that multiple efforts made for theoretic research and practical implementation of information systems has resulted in many successful applications, many of which, however, lack systemic view and cannot offer any coordinated and controlled approach to link methods together into a methodology.

Usage of agent-based DSSs in many applications provided with multiple data mining tools and permitted discover systemic properties of environmental domains.

Nevertheless, the overview has demonstrated that it is not possible to create a universal methodology for design of decision support systems for environmental domains. This goal is extremely difficult to achieve because we have to take into account the similarities shared by diverse domains without losing their specific features. However there are many solutions and multi-function tools, decision support systems perform better results when oriented to limited and determined domains.

The problem lies in the existence of a great number of overlapping approaches and methodologies which demonstrate successful results, but nevertheless fail to meet the needs of decision makers for an integrated methodology which supports decision making. However two solutions can be proposed: first, bring together existing methods for decision support systems creation within a more coherent system; second, provide an interdisciplinary flexible methodology for complex, systemic policies.

\section{REFERENCES}

[1] C.Carlsson, and E. Turban., "DSS Directions for the Next Decade". Decision Support Systems Volume: 33. (2). 105-110.,2002.

[2] A. Fernández-Caballero, M. Sokolova. Computational agents in complex decision support systems. Handbook on Decision Making, Intelligent Systems Reference Library 4, pp. 117-142. SpringerVerlag., 2009.
[3] R. Dyer and E. Forman. "Group decision support with the analytic hierarchy process". Decis. Support Syst. 8, 2 (April 1992), 99-124. 1992.

[4] M.Renger, G Kolfschoten, and G-J de Vreede , "Challenges in Collaborative Modeling: A Literature Review", Lecture Notes in Business Information Processing, 10, 61-77. 2008.

[5] S. Pallottino, G. Sechi, and P. Zuddas. "A DSS for water resources management under uncertainty by scenario analysis". Environ. Model. Softw. 20, 8 (August 2005), 1031-1042. 2005.

[6] H. Scholten, A.Kassahun, J.Refsgaard, T. Kargas, C.Gavardinas, and A.Beulens. "A methodology to support multidisciplinary model-based water management." Environ. Model. Softw. 22, 5 (May 2007), 743759. 2007.

[7] A. Fernández-Caballero and J. M. Vega-Riesco. "Determining heart parameters through left ventricular automatic segmentation for heart disease diagnosis." Expert Syst. Appl. 36, 2 (March 2009), 2234-2249. 2009.

[8] P. Keen. "Decision support systems: the next decade." Decis. Support Syst. 3, 3 (September 1987), 253-265. 1987.

[9] C. Leondes, Neural Network Systems Techniques and Applications, Seven-Volume Set: Fuzzy Logic and Expert Systems Applications, Volume 6, 1997

[10] Y. A. Lussier, R. Williams, J.Li, S. Jalan, T.Borlawsky, E. Stern, and I.Kohli. "Partitioning knowledge bases between advanced notification and clinical decision support systems". Decis. Support Syst. 43, 4 (August 2007), 1274-1286. 2007.

[11] T. G. Nguyen, J. L. de Kok, and M. J. Titus. "A new approach to testing an integrated water systems model using qualitative scenarios." Environ. Model. Softw. 22, 11 (November 2007), 1557-1571. 2007.

[12] R.Annicchiarico, U.Cortés, and C.Urdiales. "Agent Technology and eHealth. Whitestein Series in Software Agent Technologies and Autonomic Computing", 2008, 148 p.

[13] H. Gonzalez-Velz, M. Mier, C. Arus, B. Celda, S. van Huffel, P. Lewis, A. Peet, and M. Robles, "Agent-Based Distributed Decision Support System for Brain Tumour Diagnosis and Prognosis", International Conference on Multidisciplinary Information Sciences and Technologies, Open Institute of Knowledge, 288-292. 2006.

[14] I. Athanasiadis, P. Mitkas, "An agent-based intelligent environmental monitoring system", Management of Environmental Quality: An International Journal, Vol. 15 Iss: 3, 2004, pp.238 -249

[15] I. Athanasiadis, P. Mitkas, 2005. "Social Influence and Water Conservation: An Agent-Based Approach". In Computing in Science and Engg. 7, 1 (January 2005), 65-70.

[16] V.Gorodetski, O.Karsaev, V.Samoilov, V.Konushy, E.Mankov, and A.Malyshev. "Multi-agent system development kit: MAS software tool implementing Gaia methodology." In Intelligent information processing II, Zhongzhi Shi and Qing He (Eds.). Springer-Verlag, London, UK 69-78. 2004

[17] T.C. Ly, S. Greenhill, S. Venkatesh, A.Pearce, "Multiple hypotheses situation assessment", Proceedings of the Sixth International Conference on Information Fusion 2003, pp. 972-978, 2003

[18] D. Urbani and M. Delhom. "Analyzing knowledge exchanges in hybrid MAS GIS decision support systems, toward a new DSS architecture." In Proceedings of the 2nd KES International conference 
on Agent and multi-agent systems: technologies and applications (KES-AMSTA'08), Ngoc Thanh Nguyen, Geun Sik Jo, Robert J. Howlett, and Lakhmi C. Jain (Eds.). Springer-Verlag, Berlin, Heidelberg, 323-332. 2008.

[19] Li,S. "AgentStra: an Internet-based multi-agent intelligent system for strategic decision-making", Systems with Applications, Vol. 33, No. 3. (October 2007), pp. 565-571. 2007.

[20] C.-L. Chang. "A study of applying data mining to early intervention for developmentally-delayed children". Expert Syst. Appl. 33, 2 (August 2007), 407-412. 2007.

[21] H.Chen; M. Bell "Instrumented city database analysts using multiagents", Transportation Research Part C: Emerging Technologies, Volume 10, Number 5, October 2002 , pp. 419-432(14), 2002.

[22] D.Foster, C. McGregor, and S. El-Masri, "A survey of agentbased intelligent decision support." In 4th International Joint Conference on Autonomous Agents and Multiagent Systems (AAMAS 2005), July 25-29, 2005,Utrecht, The Netherlands, MASBIOMED'05 (2006), p. 104-112. 2002.

[23] D.Riaño, M. Sanchez-Marré, and, I.R.-Roda "Autonomous agents architecture to supervise and control a wastewater treatment plant." In Proceedings of the 14th International conference on Industrial and engineering applications of artificial intelligence and expert systems: engineering of intelligent systems (2001), vol. 2070 of Lecture Notes In Computer Science, pp. 804 - 811.

[24] L. Cescarroni, U.Cortés, AND M. Sanchez-Marré. "Ontowedss: augmenting environmental decision-support systems with ontologies." Environmental Modelling and Software 19, 9 (2004), pp.785797.

[25] M.Nastar, P.Wallman "An interdisciplinary approach to resolving conflict in the water domain." In Information Technologies in Environmental Engineering Proceedings of the 4th International ICSC Symposium Thessaloniki, Greece (2009), pp. 411-424.

[26] J.Rotmans. "Tools for Integrated Sustainability Assessment: A twotrack approach. Integrated Assessment" 6, 4 (2006), pp.35-57.

[27] A. J.Jakeman, R. A. Letcher. "Integrated assessment and modelling: features, principles and examples for catchment management." Environmental Modelling \& Software 18, 6 (2003), pp.491 - 501.

[28] R.Letcher, B.Croke, A. Jakeman. "Integrated assessment modelling for water resource allocation and management: A generalized conceptual framework". Environmental Modelling \& Software 22, 5 (2007), pp.733 - 742.

[29] L.Basson, J.Petrie. "An integrated approach for the consideration of uncertainty in decision making supported by life cycle assessment." Environmental Modelling \& Software 22, 2 (2007), pp.167 - 176.

[30] D. Torii, T. Ishida, S.Bonneaud, A. Drogoul. "Layering social interaction scenarios on environmental simulation." In Multi-Agent and Multi-Agent-Based Simulation (2004), vol. 3415/2005 of Lecture Notes in Computer Science, pp. 78-88.

[31] F. Harmsen, S. Brinkkemper, J. L. H.Oei, "Situational method engineering for informational system project approaches." In Proceedings of the IFIP WG8.1 Working Conference on Methods and Associated Tools for the Information Systems Life Cycle (1994), Elsevier Science Inc., pp. 169-194.
[32] R. Kaiser, I. Romieu, S. Medina, J. Schwartz, M. Krzyzanowski, N. Kunzki. "Air pollution attributable postneonatal infant mortality in U.S. metropolitan areas: A risk assessment study." Environmental Health: A Global Access Science Source (2004), pp.4-26.

[33] F.Karaka, I. Anil, O.Alagha, F. Camci. "Traffic related PM predictor for Besiktas, Turkey." In Information Technologies in Environmental Engineering, Proceedings of the 4th International ICSC Symposium, ITEE 2009, Thessaloniki, Greece, May 28-29, 2009 (2009), pp. 317-330.

[34] D. E. Saraga, A.Sfetsos, S. Andronopoulos, A.Chronis, T.Maggos, D.Vlachogiannis, J. G.Bartzis. "An investigation of the parameters influencing the determination of the number of particulate matter sources and their contribution to the air quality of an indoor residential environment." In Information Technologies in Environmental Engineering, Proceedings of the 4th International ICSC Symposium, ITEE 2009, Thessaloniki, Greece, May 28-29, 2009 (2009), pp. 453-464.

[35] R.Herrler, C. Heine, "Approaches and tools to optimize and manage clinical processes." In Application of Agents and Intelligent Information Technologies), IGI Publishing, USA, 2007, 39-65.

[36] T. Ly, S.Greenhill, S.Venkatesh, A.Pearce. "Multiple hypothesis situation assessment." In The 6th International Conference on Information Fusion (FUSION 2003) (Brisbane, Australia, 2003).

[37] S. Ossowski, A. Fernandez, J. M. Serrano, J. L. Perez-de-la Cruz, M. V. Belmonte, J. Z. Hernandez, A. M. Garcia-Serrano, J. M Maseda,. "Designing Multiagent Decision Support System "The 230 Bibliography Case of Transportation Management”. In AAMAS '04: Proceedings of the Third International Joint Conference on Autonomous Agents and Multiagent Systems (Washington, DC, USA, 2004), IEEE Computer Society, pp. 1470-1471.

[38] S.Ossowski, J. Z. Hernández,. M.-V.Belmonte, J.-M.Maseda, A. Fernández, A. García-Serrano, F. Triguero-Ruiz, J. M., Serrano, J.-L.Perez-de-La-Cruz. "Multi-Agent Systems For Decision Support: A Case Study In The Transportation Management Domain." Applied Artificial Intelligence 18, 9-10 (2004), pp.779-795.

[39] A. V.Smirnov, M.Pashkin, T.Levashova, N.Shilov, A.Kashevnik. "Rolebased decision mining for multiagent emergency response management". In Autonomous Intelligent Systems: Multi-Agents and Data Mining (2007), pp. 178-191.

[40] D. Briggs, "A framework for integrated environmental health impact assessment of systemic risks". Environmental Health, 2008, 7, pp.61-72.

[41] F. Kebair, F. Serin. "Multiagent Approach for the Representation of Information in a Decision Support System." In Artificial Intelligence: Methodology, Systems, and Applications 12th International Conference, AIMSA 2006 (2006), Lecture Notes in Computer Science, Springer Berlin / Heidelberg, pp. 98-107.

[42] M. S. Levin. Composite Systems Decisions (Decision Engineering). Springer-Verlag New York, Inc., Secaucus, NJ, USA, 2006.

[43] A. L. Symeonidis, I. Athanasiadis, P. Mitkas. "A retraining methodology for enhancing agent intelligence." Knowledge-Based Systems 20, 4 (2007), pp.388-396.

[44] K.Kumar, R. J. Welke. "Methodology Engineering R: A proposal for situation-specific methodology construction". pp.257-269. 
[45] F.Bergenti, M.-P. Gleizes, F.Zambonelli., Eds. Methodologies and Software Engineering for Agent Systems. The Agent-Oriented Software Engineering Handbook. Series: Multiagent Systems, Artificial Societies, and Simulated Organizations, Springer-Verlag New York, Inc., 2004.

[46] L.Sterling, K. Taveter. The Art of Agent-Oriented Modeling. The MIT Press, 2009.

[47] B.Henderson-Sellers, P.Giorgini., Eds. Agent-oriented methodologies. Idea Group Publishing, 2005.

[48] A. van Lamsweerde. "Goal-Oriented Requirements Engineering: A Guided Tour". In Proceedings of the 5th IEEE International Symposium on Requirements Engineering, RE'01 (2001), pp. 249-263.

[49] M.Fowler, K. Scott. UML distilled: applying the standard object modeling language. Addison-Wesley Longman Ltd., Essex, UK, 1997.

[50] P.Burrafato, M.Cossentino. "Designing a multi-agent solution for a bookstore with the PASSI methodology". In AOIS '02, Agent-Oriented Information Systems, Proceedings of the Fourth International Bi-Conference Workshop on Agent-Oriented Information Systems (AOIS-2002 at CAiSE*02) (2002), pp. 102-118.

[51] F.Giunchiglia, J.Mylipoulos, A.Perini The Tropos Software Development Methodology: Processes, Models and Diagrams. 2003, pp. $162-73$.

[52] J. Thangarajan, L.Padham, M.Winikoff. "Prometheus design tool". In AAMAS '05: Proceedings of the fourth international joint conference on Autonomous agents and multiagent systems (2005), ACM, pp. 127-128.

[53] M. Sokolova, A. Fernández-Caballero. Supporting multi-agent systems life cycle by integrating Protégé and Prometheus. International Journal of Intelligent Information and Database Systems, 4 (3), pp. 227-244. ISSN 1751-5858., 2010.

[54] C.A.Iglesias, M.Garijo, J.Centeno-Gonzalez, J. R. Velazco. "Analysis and Design of Multiagent Systems Using MAS-Common KADS". In ATAL '97: Proceedings of the 4th International Workshop, 1997.

[55] D.Coleman, P.Arnold, S.Bodoff, C.Dolin, H.Gilchrist, F.Hayes, P.Jeremaes. Object-Oriented Development: The Fusion Method, Prentice-Hall International ed. Prentice-Hall, 1994.

[56] M. Wooldridge, N. R. Jennings, D. Kinny. "The Gaia methodology for agent-oriented analysis and design." Autonomous Agents and Multi-Agent Systems 3, 3 (2000), pp.285-312.

[57] P. Kruchten. The Rational Unified Process: An Introduction (2nd Edition). Addison-Wesley Professional, Boston, MA, 2000.

[58] C.Bernon, M.-P.Gleizes, S.Peyruqueou, G.Picard. "ADELFE: A Methodology for Adaptive Multi-agent Systems Engineering. In Engineering Societies in the Agents World III, Third International Workshop, ESAW 2002 (2002), vol. 2577 of Lecture Notes in Computer Science, pp. 156-169.

[59] C.Bernon, M.-P.Gleizes, S.Peyruqueou, G.Picard ADELFE: A methodology for adaptive multi-agent systems engineering. Engineering Societies in the Agents World III (2003), pp.70-81.
[60] B.Bauer, J.P.Muller, J.Odell. "AgentUML: A formalism for specifying multiagent software systems". International Journal of Software Engineering and Knowledge Engineering 11, 3 (2001), pp.207-230.

[61] G. Caire, W. Coulier, F. J. Carijo, J. Gómez, J. Pavón, F. Leaf, P. Chainho, P. E. Kearney, J. Stark, R. Evans, and P. Massonet. "Agent oriented analysis using message/UML". In AOSE '01: Revised Papers and Invited Contributions from the Second International Workshop on Agent-Oriented Software Engineering II (London, UK, 2002), Springer- Verlag, pp. 119-135.

[62] G.Wagner, K.Taveter. "Towards radical agent-oriented software engineering processes based on aor modeling". In IAT '04: Proceedings of the Intelligent Agent Technology, IEEE/WIC/ACM International Conference (2004), pp. 509-512.

[63] J. J. Gómez-Sanz, J. Pavón. "Agent oriented software engineering with MESSAGE". In AOIS '02, Agent-Oriented Information Systems, Proceedings of the Fourth International Bi-Conference Workshop on Agent-Oriented Information Systems (AOIS-2002 at CAiSE*02) (2002), pp. 89-98.

[64] P. Kruchten. The Rational Unified Process: An Introduction (2nd Edition). Addison-Wesley Professional, Boston, MA, 2000.

[65] Fernández-Caballero, J.Gascueña. "Developing Multi-Agent Systems through Integrating Prometheus, INGENIAS and ICARO-T." The Agents and Artificial Intelligence (in press) (2010).

[66] S. A. DeLoach, M. F. Wood, C. H. Sparkman. "Multiagent systems engineering." International Journal of Software Engineering and Knowledge Engineering 11, 3 (2001), pp. 231-258.

[67] Q.-N. N. Tran, B.Henderson-Sellers, J. K. Debenham. "Incorporating the elements of the MaSE methodology into Agent OPEN". In ICEIS 2004, Proceedings of the 6th International Conference on Enterprise Information Systems, Porto, Portugal, April 14-17 (2004), pp. 380-388.

[68] B.Henderson-Sellers, J. K. Debenham., Q.-N. N.Tran. "Adding agent-oriented concepts derived from Gaia to Agent OPEN". In Advanced Information Systems Engineering, 16th International Conference, CAiSE 2004, Riga, Latvia, June 7-11, 2004, Proceedings (2004), vol. 3084 of Lecture Notes in Computer Science, Springer, pp. 98-111. 


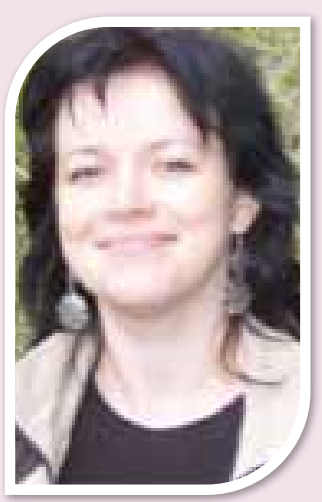

Marina V.Sokolova.

Born in Kursk, Russian Federation, in 1977, graduated from the Engineering Department in 2000, and in 2004 obtained her Ph.D. in "Administration in complex systems" from the Kursk State Technical University and in 2010 she obtained her Ph.D. in Advanced Informatics from the University of Castilla-La Mancha, Spain. Now she is an associate professor of the Safety of Vital Activity Department of the South-west University, Russia, and is a member of the research group nI\&alS (natural and artificial Interaction Systems) belonging to LoUISE (Laboratory of User Interaction and Software Engineering) of the Albacete Research Institute of Informatics, Spain. Marina V. Sokolova is interested in complex systems, systems for decision support and multi-agent systems.

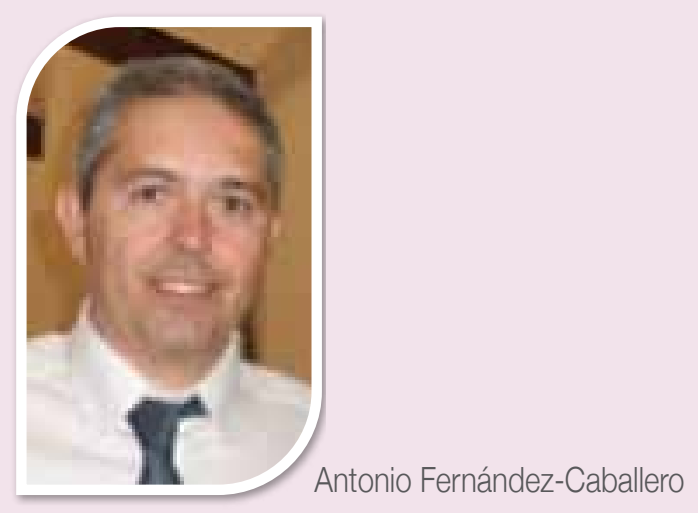

Born in Granada, Spain, in 1961, received his degree in Computer Science from the Technical University of Madrid, Spain, in 1993, and received his Ph.D. from the Department of Artificial Intelligence of the National University for Distance Education, Spain, in 2001.
Since 1995, he is an Associate Professor with the Department of Computer Science at the University of Castilla-La Mancha, Spain. He is the director of the research group ni\&alS (natural and artificial Interaction Systems) belonging to LOUISE (Laboratory of User Interaction and Software Engineering) of the Albacete Research Institute of Informatics, Spain. His research interests are in Image Processing, Cognitive Vision, Neural Networks, and Intelligent Agents. A. FernándezCaballero is an Associate Editor of the Pattern Recognition Letters journal and a member of the IAPR. He has authored more than 180 peer reviewed papers.

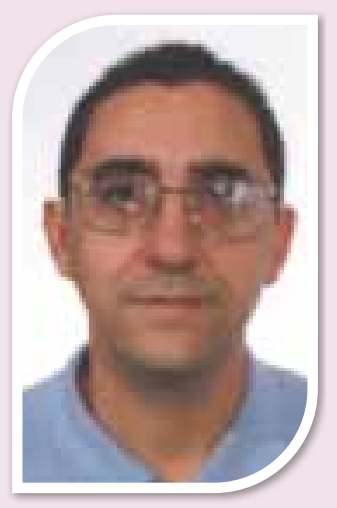

Francisco J.Gómez

Born in Jaen, Spain, in 1967, received his degree in Computer Science from the University of Granada, Spain, in 1991. Since 1992 he is an Associate Professor with the Department of Computer Science at the University of Castilla-La Mancha, Spain. and is a member of the research group nl\&alS (natural and artificial Interaction Systems) belonging to LoUISE (Laboratory of User Interaction and Software Engineering) of the Albacete Research Institute of Informatics, Spain.

Cooperantes en Investigación con el área de Pos- 